water pond $20 \mathrm{ft}$. deep with facilities for mounting the freshly discharged fuel elements in a lattice containing a number of irradiation positions. The material to be irradiated is placed in watertight cylinders (35 or $7 \frac{1}{4} \mathrm{in}$. diam. and 30 or $48 \mathrm{in}$. long) which are then lowered through the water shield to the irradiation position. The pond usually contains more than a megacurie of fuel element activity and will give up to 4 megarads/hr. in the small irradiation cans. The present charges for irradiation in this unit work out at about $10 \mathrm{~s}$. per megarad to a cubic foot of material.

In addition to the cobalt and fuel element sources, there is a $4-\mathrm{M} \theta \mathrm{V}$. linear accelerator with a $2-\mathrm{kW}$. electron beam output. It is used principally for treating small samples to high dose-levels of the order of $10^{8}$ rads and also to study dose-rate effects. It gives doserates a hundred times higher than those available from the gamma cells.

The Division has medium-level and tracer-level chemical laboratories. The fields covered are wide and include the incorporation of isotopes in colloids for medical studies, improved methods of synthesis of labelled compounds, the use of autoradiography as an analysical tool in metallurgy, and the operation of an activation analysis service for other laboratories.

In the physics laboratory a section works in close collaboration with the National Physical Laboratory and other national laboratories on the absolute measurement of radioactivity. It has established standards of radioactivity and issues standards for many isotopes not yet covered by the standards service of the Radiochemical Centre. The work on instruments and radiation detection is largely directed towards widening the fields of application of gauges using radioactive sources and increasing the sensitivity and discriminating powers of detectors so that tracer uses of isotopes can be extended without increasing the quantity of isotope used.

An essential feature of the work of the Research Laboratory is to discover those industrial processes and fields of industrial and academic research where advantages can be gained by the introduction of instruments or techniques using radioactive materials. An experimental and advisory service is operated which will visit firms and discuss general and particular problems, and on a payment basis will make special investigations either on the firm's premises or back in the laboratories. To further this objective, exchange visits are made with the research associations of many trades, and the Department of Scientific and Industrial Research has attached a small group which uses the facilities of the laboratories and acts as a further contact with research and industry.

For a fixed capitation fee, firms can attach a scientist to the laboratory to work on a problem of either general or commercial interest. In this way a satisfactory blending of the skills of the firm in its own field with the facilities and experience of the Laboratory is achieved.

No outline of the facilities of the Laboratory would be complete without mention of the Isotope School. It was first set up at Harwell in 1951 to give basic training in the uses of radioisotopes in research, industry, and medicine. It is open to students from all countries, and provides a basic four-weeks' course several times a year, together with a number of courses on specialized subjects such as medical applications, radiological protection and autoradiography.

\title{
PROTECTION AGAINST TIDAL FLOODING IN LONDON
}

$\mathrm{M}$ EMORIES of the effects on the east coast of Britain of the disastrous storm surge of January 31-February 1, 1953, are beginning to dim. A Government report ${ }^{1}$, which has recently been published, is therefore a timely reminder that in the vitally important London area there is no justification for complacency concerning the present degree of protection against tidal flooding.

It is true that in 1953 the low-lying areas of London escaped flooding, but the water lapped the top of the defences at many points so that the margin of safety must have been very small. Thus the question might well be asked as to how it is that seven years afterwards the defences of London are still virtually the same, whereas at almost all other vulnerable points on the east coast of Britain they have been greatly strengthened. As will be seen, the explanation lies in the complexity of the problem and the high capital cost of a solution.

In 1953 the maximum level of the surge-cum-tide at London Bridge was $6 \mathrm{ft}$. above predicted high water. When considering the possibility of a future even higher maximum level, there are four significant features of the 1953 event which should be borne in mind : $(a)$ the river discharge was low-only 2,600 cu. ft./sec.; (b) the normal tide on which the surge was superimposed was a spring tide, but not a particularly high one; $(c)$ the peak of the surge did not coincide with the time of predicted high water, but preceded it by about $2 \mathrm{hr}$.; (d) considerable breaching and overspill into low-lying areas occurred farther down the estuary.

Any of these features could have been more adverse, in addition to which the magnitude of the surge itself might have been slightly greater. In order to investigate these possibilities, tests were carried out on a hydraulic model ${ }^{2}$ of the Thames estuary. It was deduced that a major river flood of $20,000 \mathrm{cu}$. ft./sec. would have raised the 1953 level by 9 in. ; also that an increase of $1.5 \mathrm{ft}$. in the surge height at Southend (or a correspondingly less favourable phasing with tide) would have added about $1.7 \mathrm{ft}$. at London Bridge, while a $3 \mathrm{ft}$. increase would have added about $3 \mathrm{ft}$. at the same point. The relief due to storage in low-lying areas was shown to be quite small - not more than 3 in. Owing to raising of the banks this should be discounted in the future.

Thus it appears that a surge $1.5 \mathrm{ft}$. higher, coinciding with a freshwater flood, would raise water-levels by about $2 \cdot 7 \mathrm{ft}$. above those of 1953 . If the extreme, though exceedingly remote, case be considered of the highest possible surge coinciding with a peak spring tide and a freshwater flood, then the resultant waterlevels might be expected to be about $6 \mathrm{ft}$. above 1953 . 
Also, it should be pointed out that a long-term consideration would need to take into account the relative rise in sea-level, which in south-east England is about $1 \mathrm{ft}$. a century.

The Waverley Committee ${ }^{3}$ was very mindful of the position at London and a special section of its report, submitted in 1954, was devoted to a consideration of the problems of protection. It suggested two alterna tive schemes as meriting further investigation : a direct raising of the riparian defences, or the construction of a movable barrier across the river. The latter would clearly be a formidable engineering undertaking, involving technical problems of a difficult and unusual nature. It appeared to the Committee that the best site would be in Long Reach between Purfleet and Greenhithe.

In accordance with the Committee's recommendations, a technical panel was constituted in 1954 for the purpose of studying both these proposals. The recently published report, briefly outlined in what follows, is a summary of the findings of the Panel, together with those of the engineering consultants who were afterwards appointed to make a preliminary technical report on the barrier scheme.

\section{Defence Measures}

The cost of raising the riparian defences to a height 2-3 ft. above the 1953 water-levels would be in the region of $£ 10$ million; to which would have to be added a considerable but unknown sum in respect of compensation to frontagers.

The location and design of a barrier would have to satisfy both flood protection and shipping interests. From each of these points of view the Long Reach site was acknowledged to be the most favourable. With regard to design, however, the stipulations made on navigational grounds were particularly severe. These were that two clear openings of about $500 \mathrm{ft}$. width should be provided, with a minimum vertical clearance of about $230 \mathrm{ft}$. Additional smaller waterways would be required for light craft. At all times, except when a dangerous surge was present or imminent, the barrier should be open to the free passage of shipping.

Under the flood warning system, which is at present in operation on the east coast, about $6 \mathrm{hr}$. notice of a potentially dangerous surge is received and this would enable the barrier to be closed when the waterlevels wero relatively low. After closure, water-levels would build up independently on either side and the consequent differential pressure head would havo to be allowed for in the design of the gates. On the riverine side, the reservoir capacity would have to be sufficient to contain a freshwater flood for the duration of closure. On the estuarine side the gates would have to be of sufficiont height to withstand a surge-cumtide $6 \mathrm{ft}$. higher than 1953 . Also the reflected tidal wave should not cause overspill into important lowlying areas.

With these broad terms of reference, the engineering consultants examined the problem and decided that there were only two types of barrier which could be recommonded as being suitable, namely: (a) the vertical lifting bridge type; (b) the swing bridge type.

The lifting bridge type would consist of three main piers each $75 \mathrm{ft}$. wide supporting towers $320 \mathrm{ft}$. high. Between the towers, lifting bridge spans would be suspended and on the lower side these would carry hinged gates. With the barrier open the bridges would be in the fully raised position. When closure was necessary, the bridges would be lowered to just above flood-level and the hinged gates then swung downwards to come to rest in the vertical position against the concrete sill at the bed of the river. A somewhat similar, but much smaller barrier, has recently been constructed on the River Ijssel, Holland. Experience gained in its operation should prove invaluable.

The swing bridge type would have a similar founda. tion design to that just described, but the three central piers would have a much greater length in the direction of flow. Three lattice girder swing spans would be pivoted on the piers and these would carry the hinged gates in the same manner as in the first type. On closure, the spans would swing on their pivots, meeting in the centre of the two main waterways.

The lifting type would be better for navigation, owing to the shorter piers, whereas the swing bridge type would be easier to maintain. The estimatod cost of the swing bridge type is lower--between $£ 13$ and $£ 15$ million as compared with between $£ 15$ and $£ 17$ million. Further experiments and investiga. tions would be required before a final choice could be made.

From the flood protection aspect, the barrier scheme is decidedly preferable to the raising of the riparian defences, since the former would provide a standard of protection $6 \mathrm{ft}$. above 1953 levels whereas the latter could only reasonably be raised by about $3 \mathrm{ft}$.

The next stage is that consultations between interested parties will take place with the view of establishing the degree of support for the proposals and considering the arrangements for putting them into effect.

\section{Flood Economics}

It is often found with flood protection works, and the case of London is no exception, that the capital cost is high and the need only patently demonstrated at infrequent occasions. In these circumstances, there is an understandable tendency for the urgeney accorded to a particular scheme to diminish progressively with the time which has elapsed since the last flood. A gamble with fate is tempting when the odds are long, but it is generally advisable to be cognizant of the stakes.

The worthwhileness of a protection scheme may be assessed on an economic basis. This entails a comparison between the cost of protecting against a particular flood, and the cost of the damage which would otherwise result. It is of course necessary to take into account the likely interval of recurrence of the flood, and this may be estimated by statistical methods.

The danger to public safety and the damage which would be associated with various degrees of overspill in London have not been generally made known. It is significant, however, that the Dutch are planning the Delta scheme on the basis of a flood with a 10,000-year recurrence interval. This standard may be compared with the estimated 400-year interval of the 1953 flood.

N. B. WEBBER

\footnotetext{
1 "Technical Possibilities of a Thames Flood Barrier". Pp. $30+$ 3 plates. (Cmnd. 956.) (London: H.M. Stationery Office, 1960.) $3 s$. $6 d$. net.

${ }^{2}$ Allen, F. H., Price, W. A., and Inglis, C. C., Proc. Inst. Civ. Eng., 4 Pt. 3,48 (1955).

s "Report of the Departmental Committee on Coastal Flooding". (Cmnd. 9165.) (London: H.M. Stationery Office, 1954.)
} 